\title{
Optically transparent vertical silicon nanowire arrays for live-cell imaging
}

\author{
Roey Elnathan ${ }^{1,2,3^{*}+}$ (D) Andrew W. Holle ${ }^{4,5+}$, Jennifer Young ${ }^{4,5+}$, Marina A. George ${ }^{2,3}$, Omri Heifler ${ }^{6,7}$, \\ Andriy Goychuk ${ }^{8}$, Erwin Frey ${ }^{8}$, Ralf Kemkemer ${ }^{10,11}$, Joachim P. Spatz ${ }^{10,12}$, Alon Kosloff ${ }^{6,7^{*}}$, \\ Fernando Patolsky ${ }^{6,7^{*}}$ and Nicolas H. Voelcker ${ }^{1,2,3,9^{*}}$
}

\begin{abstract}
Programmable nano-bio interfaces driven by tuneable vertically configured nanostructures have recently emerged as a powerful tool for cellular manipulations and interrogations. Such interfaces have strong potential for ground-breaking advances, particularly in cellular nanobiotechnology and mechanobiology. However, the opaque nature of many nanostructured surfaces makes non-destructive, live-cell characterization of cellular behavior on vertically aligned nanostructures challenging to observe. Here, a new nanofabrication route is proposed that enables harvesting of vertically aligned silicon (Si) nanowires and their subsequent transfer onto an optically transparent substrate, with high efficiency and without artefacts. We demonstrate the potential of this route for efficient live-cell phase contrast imaging and subsequent characterization of cells growing on vertically aligned Si nanowires. This approach provides the first opportunity to understand dynamic cellular responses to a cell-nanowire interface, and thus has the potential to inform the design of future nanoscale cellular manipulation technologies.
\end{abstract}

Keywords: Nanowires, Cell-material interface, Live-cell phase-contrast imaging, Silicon, Glass substrate

Significant multidisciplinary progress in cellular nanotechnology has led to engineered nano-bio cellular interfaces that can stimulate and leverage cellular processes at the nanoscale [1-5]. Well-defined nanomaterial morphologies-in particular, vertically-aligned nanostructures such as nanowires, nanostraws, and nanotubes (NW, NS, and NT) - can now be interfaced with cellular systems to manipulate and interrogate cell function, behaviour, and fate [6-15]. Despite these advances, the biological response to engineered nano-bio cellular interfaces remains poorly understood. Thus, the development

\footnotetext{
*Correspondence: roey.elnathan@monash.edu; alonkosloff@gmail.com; fernando@post.tau.ac.il; nicolas.voelcker@monash.edu

${ }^{\dagger}$ Roey Elnathan, Andrew W. Holle and Jennifer Young contributed equally.

${ }^{1}$ Faculty of Pharmacy and Pharmaceutical Sciences, Monash University, Parkville, Vic 3052, Australia

${ }^{7}$ The Center for Nanoscience and Nanotechnology, Tel-Aviv University, 69978 Tel Aviv, Israel

Full list of author information is available at the end of the article
}

of new tools for directly probing this response is likely to lead to the development of novel fundamental research applications and ex vivo cell-based therapies [16-19].

The ability of these nanostructures to elicit functional cellular responses at the cell-material interface-such as intracellular delivery, biomolecular extraction (nanobiopsy), nanoelectrode-based electrophysiology, biosensing, and mechanotransduction-arises from their salient advantages in multiple independent parameters: geometric/architectural flexibility, minimal invasiveness, and the ability to simultaneously interface with large numbers of cells [20-25].

Despite implementation of these platforms in a variety of advanced cellular applications-such as in vivo and ex vivo gene editing, recording cellular action potential, and immunomodulation-the development of this burgeoning field is hindered by a lack of tools allowing for direct, rapid, and dynamic visualization of living cells interacting with these nanostructures [26-32].

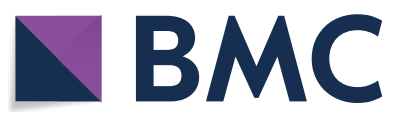

(c) The Author(s) 2021, corrected publication 2021. This article is licensed under a Creative Commons Attribution 4.0 International License, which permits use, sharing, adaptation, distribution and reproduction in any medium or format, as long as you give appropriate credit to the original author(s) and the source, provide a link to the Creative Commons licence, and indicate if changes were made. The images or other third party material in this article are included in the article's Creative Commons licence, unless indicated otherwise in a credit line to the material. If material is not included in the article's Creative Commons licence and your intended use is not permitted by statutory regulation or exceeds the permitted use, you will need to obtain permission directly from the copyright holder. To view a copy of this licence, visit http://creativecommons.org/licenses/by/4.0/. The Creative Commons Public Domain Dedication waiver (http://creativeco mmons.org/publicdomain/zero/1.0/) applies to the data made available in this article, unless otherwise stated in a credit line to the data. 
Recent advances in combinatorial nanofabrication routes now offer precise control over SiNWs growth, topological parameters, and array architecture, overcoming the limitations of conventional fabrication that have restricted cell-NW studies [33-35]. Combining colloidal lithography techniques, such as convective assembly and self-assembly at liquid-liquid interfaces, with either metal-assisted chemical etching (MACE) or deep reactive ion etching (DRIE), enables controlled VA-SiNWs growth [36-38]. Other recent nanoscale patterning paradigms for overcoming bottlenecks in fabricating fully tunable SiNW arrays over large areas have been demonstrated by creating defined sequential binary assemblies at fluid interfaces (combining two types of microgel sizes), and transferring them onto a Si substrate to generate a lithographic etching mask to grow binary VA-SiNW arrays [39].

Transfer of vertically and horizontally configured nanostructures from one substrate to another has been demonstrated via nanotransplantation printing [40]. Although this has mostly been applied to horizontally aligned in-plane nanostructures, it has also been utilized for the transfer of VA-SiNWs into flexible PDMS substrates for multispectral imaging applications [41-45].

These developments in nanofabrication routes have opened the doors for significant interdisciplinary opportunities. Programming SiNW arrays with adaptable architectures to function as nanoscale-enhanced tools allows for the direct and diverse manipulation of large cell populations [46-50]. Despite this, there has been almost no progress toward live-cell characterization of cell-nanostructure interfacial interactions. To address this, an efficient, flexible, and non-destructive nanofabrication route that is compatible with optical microscopy is needed.

Visualizing cells on $\mathrm{Si}$ nanostructures mostly requires fixation and subsequent epifluorescence microscopy due to the opaque nature of Si substrates. Fixed cells can also be imaged at higher resolution with the aid of advanced super-resolution microscopies, including stimulated emission depletion microscopy, stochastic optical reconstruction microscopy, and combinations of these modalities [51, 52]. Additional imaging modalities, including transmission electron microscopy (TEM), focused ion beam scanning electron microscopy (FIB-SEM), and electron tomography have all been highly effective for imaging fixed cells at the nanoscale cell-material interface $[53,54]$. Specifically, FIB-SEM lift-out of cell-nanomaterial composites-generated via FIB milling and placed directly in a customized TEM grid-in conjunction with the development of new ultrathin sectioning methods have led to a deeper understanding of how surface-based nanostructures can affect intracellular processes [55].
While these imaging strategies have greatly advanced our understanding of the cell-material interface, none are compatible with dynamic imaging of live cells on nanostructured surfaces.

\section{Results and discussion}

Here, we present a novel experimental approach that enables transfer of vertically-aligned Si nanowires from their original Si substrate onto an optically transparent glass substrate while preserving the geometrical features. We demonstrate the potential of these substrates for labelfree live-cell phase contrast imaging of dynamic cellular processes such as cell division, morphology change, and migration. This approach will advance our understanding of cellular responses to extracellular bio-physical cueswhich in turn is likely to improve the design of future cellular manipulation technologies.

Figure 1 depicts in detail the nanofabrication pipeline for the SiNW array harvesting and subsequent transfer onto transparent glass substrates. First, e-beam lithography was used to directly write a customized lithographical mask array of nanoscale-circles-200 nm diameter, $1 \mu \mathrm{m}$ pitch-on an electron-resist film coated onto a $\mathrm{Si}$ substrate. Second, a $50 \mathrm{~nm}$ thick Ni layer was evaporated and the resist layer lifted off, resulting in the formation of Ni disk-like shapes that served as programmable lithographical etching masks. Third, SiNW arrays were generated using DRIE, and the Ni etch-masks removed. This step was followed by deposition of a $30 \mathrm{~nm}$ thick Au-layer over the NW array using e-beam direct-angle evaporation. Fourth, a PMMA layer was deposited by spin coating, followed by immersion in an Au-etchant solution. This step is crucial for selectively removing the residual Au-layer on the top and sidewalls of the NWs. The remaining $\mathrm{Au}$ layer on the bottom of the SiNW substrate served as an anti-adhesion agent, which later promoted

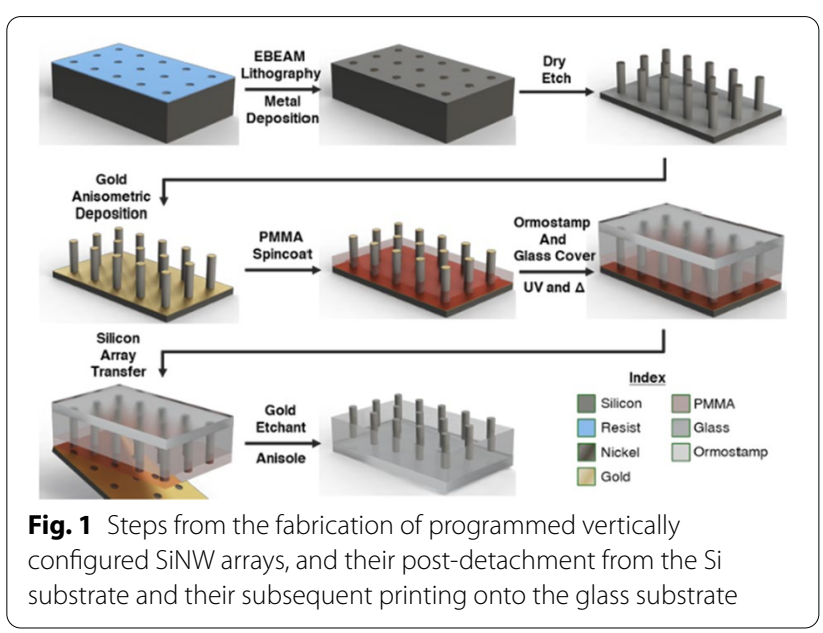


the NW arrays' selective harvesting and their subsequent transfer from the $\mathrm{Si}$ donor substrate onto the acceptor transparent glass substrate. The PMMA resist layer served as a lower embedding layer that could be further removed after the imprint process. Fifth, a silicate-based UV-curable Ormostamp solution was cast on top of the donor substrate NW array; the acceptor glass substrate was then placed precisely above the SiNW arrays (sandwich-type interface), followed by a UV curing step. Sixth, once cured, the Si-donor and glass-acceptor substrates were mechanically separated by placing a razor blade between the samples (only at the corner, without touching the pillar array), while applying a small force.

(Figure 2a, b) shows zoom-out and zoom-in SEM images SiNW arrays that were generated using DRIE. (Figure 2c, d) shows optical and SEM images of the Sidonor substrate after SiNW array harvesting. The NW array was successfully transferred onto the glass substrate along with its embedded cured-Ormostamp/PMMA/ $\mathrm{Au}$ layers. The NW array was exposed through immersion in Au-etchant solution followed by removal of the
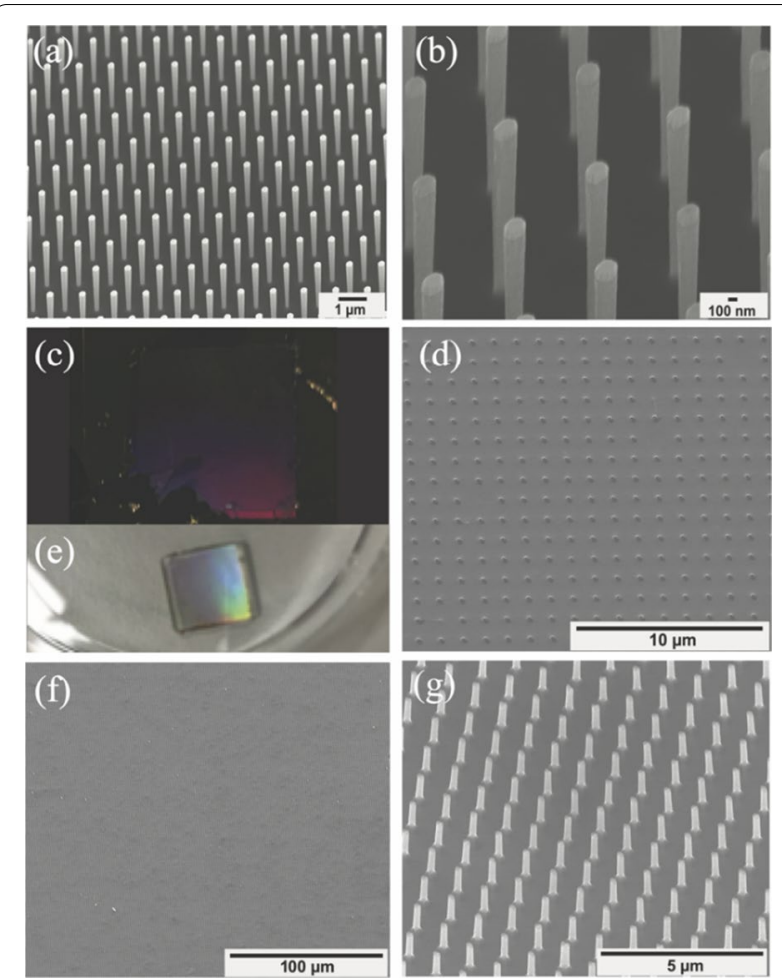

Fig. 2 SiNW fabrication and their subsequent transfer onto an optically transparent substrate. $\mathbf{a}, \mathbf{b}$ SEM images of the negatively tapered SiNW arrays fabricated via e-beam lithography and DRIE, (a) the zoom-out, and (b) the zoom-in. c, d Optical and SEM showing the Si donor substrate post-harvest. $\mathbf{e}-\mathbf{g}$ Optical image showing SiNW transfer onto a glass substrate (e); and tilt SEM images of a zoom-out and zoom-in of the transferred SiNW array onto the glass substrate top PMMA layer via immersion in anisole solution. The lower layer of the exposed nanowires remained embedded in the optically-transparent Ormostamp. This process results in accurate, precise, and high-efficiency $\mathrm{SiNW}$ array transfer from Si to glass, preserving the original programmable design (Fig. 2e-g; optical and SEM images). (Additional file 1: Figure S2) shows additional Si geometry onto an optically transparent substrate. (Additional file 1: Figure S3) shows incomplete NW transfer arrays onto the glass substrates, while (Additional file 1: Figure S4) shows destructive NW transfer on the glass substrates.

Arrays of SiNWs on glass substrates allows for the dynamic observation of cell behavior as a function of nanowire interaction over long time scales, (Fig. 3, Additional files 2, 3: Movies 1, Movie 2). Using phase contrast microscopy, cellular features like the nucleus (Fig. 3b, d; blue arrows) and lamellipodia (Fig. 3b, d; red arrows) can be observed in living MDA-MB-231 breast cancer cells growing on flat control (Fig. 3a) or SiNW substrates (Fig. 3c).

As time lapse microscopy generates hundreds of labelfree phase contrast images, the manual segmentation of
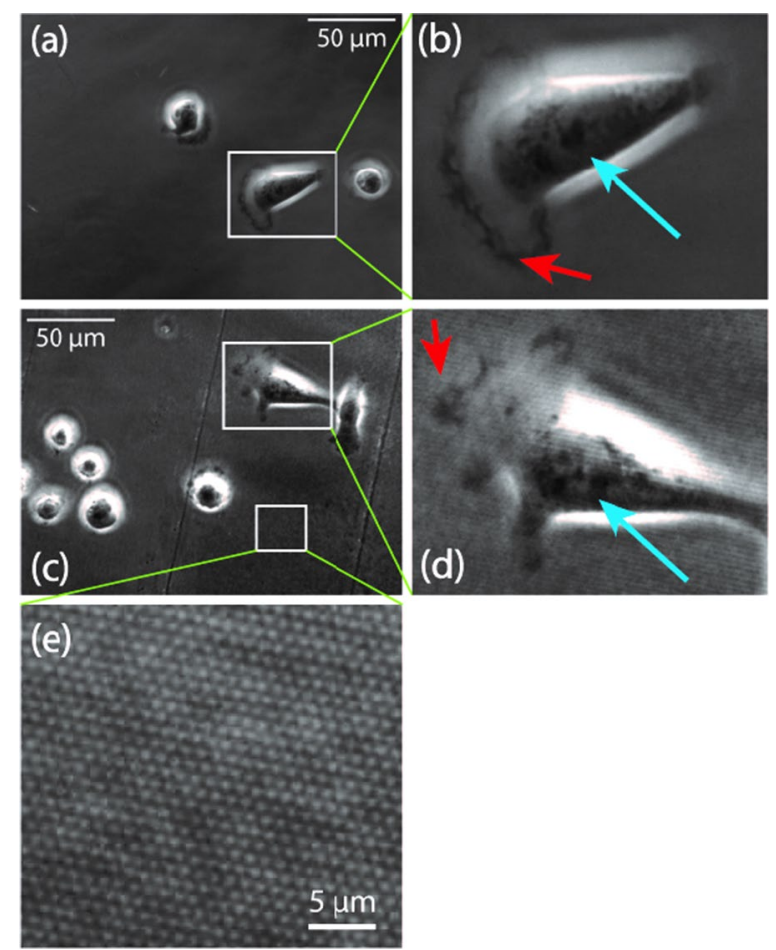

Fig. 3 Phase contrast images of MDA-MB-231 breast cancer cells cultured for over $3 \mathrm{~h}$ on flat glass $(\mathbf{a}, \mathbf{b})$ or transparent SiNW surfaces $(\mathbf{c}, \mathbf{d})$. Insets (b, d) illustrate the label-free localization of cellular nuclei (blue arrows) and lamellipodia (red arrows). Inset (e) illustrates the direct visualization of nanowire arrays by means of phase contrast microscopy 
individual cells is challenging. To address this, we trained a convolutional neural network to automatically identify and track cell outlines (Additional file 4: Movie 3). To leverage the unique advantages of our transparent SiNW arrays, we focused on dynamic cellular characteristics that would be difficult or impossible to observe in fixed cells. While fully spread cells were observed on SiNW substrates (Fig. 3d), we found that the presence of SiNWs results in significant decreases in cell area and cell velocity of MDA-MB-231 cells (Fig. 4c, d), although the initial cell viability, as measured by the number of attached cells per $\mathrm{mm}$ [2], was not affected (Figure S5). Interestingly, the number of cells undergoing division events on SiNW surfaces was significantly higher $(\mathrm{p}=0.014)$ than on control glass substrates, (Fig. 4a).

This increased division frequency, which causes cells to round up, likely also accounts for the slight decrease in cellular aspect ratio on SiNW surfaces (Fig. 4b). To date, nanowire structures have not been implicated in regulating the cell cycle, which highlights the unique void these transparent structures fill in the field of nanoscale material-cell interfaces. Future studies will likely leverage this ability to probe these phenomena, as a

Division Frequency

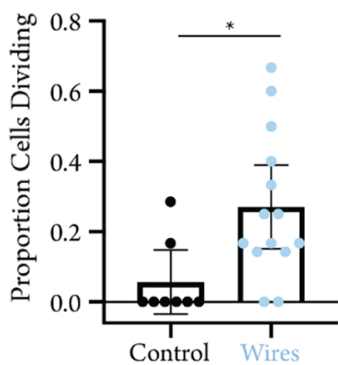

c

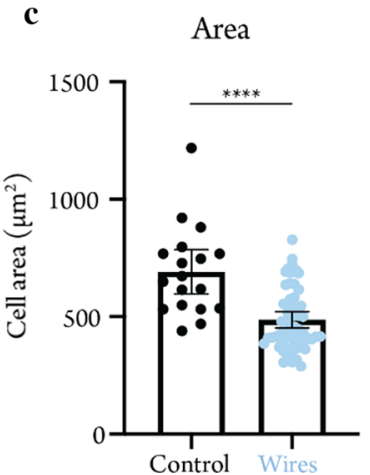

b

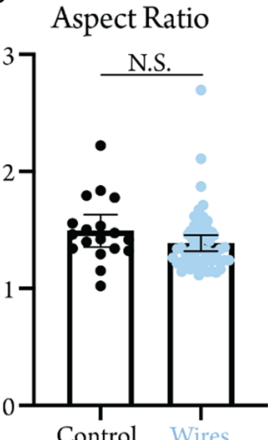

d

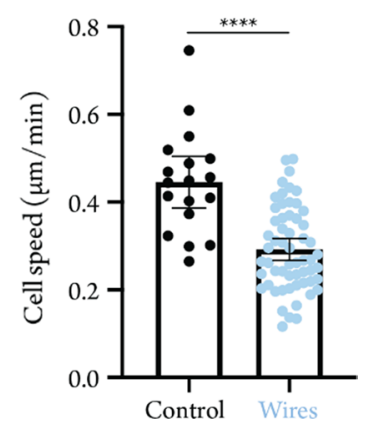

Fig. 4 Cell behaviour as a function of SiNW substrate. For division frequency (a), each circle corresponds to the proportion of cells dividing in a single field of view. For all other plots (b-d), each circle corresponds to a single cell averaged over $24 \mathrm{~h}$. Error bars represent $95 \%$ confidence intervals of the mean. ${ }^{*} p<0.05$ well as other dynamic cell behaviours, like cell spreading, contact guidance, and collective migration. Given that the highly metastatic MDA-MB-231 cells used for this experiment feature a relatively fast doubling time, it is possible that the effect on division frequency may be tempered in other lines that divide less frequently. Perhaps most intriguingly, the ability to visualize the nanowire structures directly via phase contrast microscopy (Fig. 3e) hints at the possibility of correlating directional cell behaviour, either at the whole cell scale area with respect to individual protrusions, to the alignment of the long-range nanowire patterns.

This novel experimental approach enables harvesting of vertically configured SiNWs from a Si-donor substrate and their subsequent transfer onto a glass substrate with minimal artifacts. A considerable advantage of this approach, apart from high efficiency harvesting and subsequent transfer onto an optically transparent substrate, is compatibility with live-cell phase contrast imaging. We have demonstrated proof-of-concept of dynamic characterization of cellular morphology, division, and migration, without the need for immunocytochemical markers, on a nanowire-structured substrate. This approach opens a new dimension for the ongoing study of cellular responses to nanoscale extracellular biophysical cues, which is likely to facilitate the development of improved nanoscale cellular manipulation technologies.

\section{Supplementary Information}

The online version contains supplementary material available at https://doi. org/10.1186/s12951-021-00795-7.

Additional file 1: Fig. S1. Glass substrate following the application of Ormostamp layer and separation from the Si substrate. The transferred Si-NW array with its bottom Au coating is indicated by the arrows. Fig. S2. Zoom-out and zoom-in SEM images showing an additional imprinted NW geometry: height $1 \mu \mathrm{m}$ and $0.8 \mu \mathrm{m}$ spacing. Fig. S3. SEM images showing incomplete NW transfer array onto the glass substrate. Typically, yielding $\%$ failure $<10 \%$. Fig. S4. SEM images showing destructive NW transfer array on the glass substrate. Typically, yielding $\%$ failure $<10 \%$. Fig. S5. Nanowire surfaces do not significantly affect initial cell viability less than 3 hours after plating.

Additional file 2: Video 1. Phase contrast video of MDA-MB-231 cells on a flat glass substrate.

Additional file 3: Video 2. Phase contrast video of MDA-MB-231 cells on a transparent VA-SiNW substrate.

Additional file 4: Video 3. Video of MDA-MB-231 cells with overlaid automatic cell segmentation results $(p(x, y))$ and cell contours at $p(x, y)=0.25$. The glyph ' $x$ ' denotes the respective centroid, with the current object ID.

\section{Acknowledgments}

This work was in part funded by the Australian government (ARC DECRA project number: DE170100021). A.H., J.Y., R.E., N.H.V., J.S., and R.K. acknowledge funding from Universities Australia DAAD German Research Cooperation. N.H.V. acknowledges funding from the CSIRO Research Office for a Science Leader Fellowship. The research was conducted in part at the Melbourne 
Centre for Nanofabrication (MCN) in the Victorian Node of the Australian National Fabrication Facility (ANFF). R.E thanks the Australian Friends of Tel Aviv University.

\section{Authors' contributions}

RE, AK, FP and NV developed the idea for the study and its scope and supervised the experimental team consisting of RE and $\mathrm{OH}, \mathrm{MG}$ and $\mathrm{AK}$ who developed and performed nanofabrication and its characterisation. AH, JY, RK, and JS designed and performed cellular experiments and statistical analyses. Machine learning and data analysis was performed by AG, and EF. All authors read and approved the final manuscript.

\section{Funding}

Open Access funding enabled and organized by Projekt DEAL. N.H.V., J.P.S., R.F., R.E. A. H., and J.Y., acknowledge funding from the Australia-Germany joint research co-cooperation scheme.

\section{Availability of data and materials}

All data generated or analysed during this study are included in this published article [and its Additional files 1, 2, 34].

\section{Ethics approval and consent to participate \\ Not applicable.}

\section{Consent for publication}

Not applicable.

\section{Competing interests}

The authors declare that they have no competing interests.

\begin{abstract}
Author details
${ }^{1}$ Faculty of Pharmacy and Pharmaceutical Sciences, Monash University, Parkville, Vic 3052, Australia. ${ }^{2}$ Department of Materials Science and Engineering, Monash University, 22 Alliance Lane, Clayton, Vic 3168, Australia. ${ }^{3}$ Melbourne Centre for Nanofabrication, Victorian Node of the Australian National Fabrication Facility, Victoria, Australia. ${ }^{4}$ Mechanobiology Institute, National University of Singapore, Singapore, Republic of Singapore. ${ }^{5}$ Department of Biomedical Engineering, National University of Singapore, Singapore, Republic of Singapore. ${ }^{6}$ School of Chemistry, The Raymond and Beverly Sackler Faculty of Exact Sciences, Tel-Aviv University, Tel Aviv, Israel. ${ }^{7}$ The Center for Nanoscience and Nanotechnology, Tel-Aviv University, 69978 Tel Aviv, Israel. ${ }^{8}$ Arnold Sommerfeld Center for Theoretical Physics and Center for NanoScience, Department of Physics, Ludwig-Maximilians-Universität München, 80333 Munich, Germany. ${ }^{9}$ INM-Leibnitz Institute for New Materials, Campus D2 2, 66123 Saarbrücken, Germany. ${ }^{10}$ Department of Cellular Biophysics, Max Planck Institute for Medical Research, 69120 Heidelberg, Germany.

${ }^{11}$ Department of Applied Chemistry, Reutlingen University, 72762 Reutlingen, Germany. ${ }^{12}$ Department of Biophysical Chemistry, University of Heidelberg, 69120 Heidelberg, Germany.
\end{abstract}

Received: 29 December 2020 Accepted: 6 February 2021 Published online: 17 February 2021

\section{References}

1. Lestrell E, Patolsky F, Voelcker NH, Elnathan R. Engineered nano-bio interfaces for intracellular delivery and sampling: applications, agency and artefacts. Mater Today. 2020;33:87-104.

2. Higgins SG, Becce M, Belessiotis-Richards A, Seong H, Sero JE, Stevens MM. High-aspect-ratio nanostructured surfaces as biological metamaterials. Adv Mater. 2020;32:e1903862.

3. Elnathan R, Kwiat M, Patolsky F, Voelcker NH. Engineering vertically aligned semiconductor nanowire arrays for applications in the life sciences. Nano Today. 2014;9:172-96.

4. Tay A, Melosh N. Nanostructured materials for intracellular cargo delivery. Acc Chem Res. 2019;52:2462-71.

5. He G, Hu N, Xu AM, Li X, Zhao Y, Xie X. Nanoneedle platforms: the many ways to pierce the cell membrane. Adv Func Mater. 2020;30:e1909890.
6. Chen Y, Aslanoglou S, Gervinskas G, Abdelmaksoud H, Voelcker NH, Elnathan R. Cellular deformations induced by conical silicon nanowire arrays facilitate gene delivery. Small. 2019;15:e1904819.

7. He G, Feng J, Zhang A, Zhou L, Wen R, Wu J, Yang C, Yang J, Li C, Chen D, Wang J, Hu N, Xie X. Multifunctional branched nanostraw-electroporation platform for intracellular regulation and monitoring of circulating tumor cells. Nano Lett. 2019;19:7201-9.

8. Elnathan R, Delalat B, Brodoceanu D, Alhmoud H, Harding FJ, Buehler K, Nelson A, Isa L, Kraus T, Voelcker NH. Maximizing transfection efficiency of vertically aligned silicon nanowire arrays. Adv Func Mater. 2015;25:7215-25.

9. Gopal S, Chiappini C, Penders J, Leonardo V, Seong H, Rothery S, Korchev Y, Shevchuk A, Stevens MM. Porous silicon nanoneedles modulate endocytosis to deliver biological payloads. Adv Mater. 2019;31:e1806788.

10. Wen R, Zhang AH, Liu D, Feng J, Yang J, Xia D, Wang J, Li C, Zhang T, Hu N, Hang T, He G, Xie X. Intracellular delivery and sensing system based on electroplated conductive nanostraw arrays. ACS Appl Mater Interfaces. 2019;11:43936-48.

11. He G, Yang C, Hang T, Liu D, Chen HJ, Zhang AH, Lin D, Wu J, Yang BR, Xie $X$. Hollow nanoneedle-electroporation system to extract intracellular protein repetitively and nondestructively. ACS Sens. 2018;3:1675-82.

12. Chiappini C, Martinez JO, De Rosa E, Almeida CS, Tasciotti E, Stevens MM. Biodegradable nanoneedles for localized delivery of nanoparticles in vivo: exploring the biointerface. ACS Nano. 2015;9:5500-9.

13. Kadiri VM, Bussi C, Holle AW, Son K, Kwon H, Schütz G, Gutierrez MG, Fischer P. Biocompatible magnetic micro- and nanodevices: fabrication of FePt nanopropellers and Cell transfection. Adv Mater. 2020;32:1-9.

14. Huang X, Gonzalez-Rodriguez R, Rich R, Gryczynski Z, Coffer JL. Fabrication and size dependent properties of porous silicon nanotube arrays. Chem Commun. 2013;49:5760.

15. Shpaisman N, Givan U, Kwiat M, Pevzner A, Elnathan R, Patolsky F. Controlled synthesis of ferromagnetic semiconducting silicon nanotubes. J Phys Chem C. 2012;116:8000-7.

16. Chen Y, Wang J, Li X, Hu N, Voelcker NH, Xie X, Elnathan R. Emerging roles of $1 D$ vertical nanostructures in orchestrating immune cell functions. Adv Mater. 2020;32:e2001668.

17. Zhao W, Hanson L, Lou HY, Akamatsu M, Chowdary PD, Santoro F, Marks JR, Grassart A, Drubin DG, Cui Y, Cui B. Nanoscale manipulation of membrane curvature for probing endocytosis in live cells. Nat Nanotechnol. 2017;12:750-6.

18. Dipalo M, Caprettini V, Bruno G, Caliendo F, Garma LD, Melle G, Dukhinova M, Siciliano V, Santoro F, De Angelis F. Membrane poration mechanisms at the cell-nanostructure interface. Adv Biosyst. 2019;3:e1900148.

19. Tay A, Melosh N. Transfection with nanostructure electro-injection is minimally perturbative. Adv Ther. 2019;2:e1900133.

20. Li X, Matino L, Zhang W, Klausen L, McGuire AF, Lubrano C, Zhao W, Santoro F, Cui B. A nanostructure platform for live-cell manipulation of membrane curvature. Nat Protoc. 2019;14:1772-802.

21. Lou HY, Zhao W, Zeng Y, Cui B. The role of membrane curvature in nanoscale topography-induced intracellular signaling. Acc Chem Res. 2018;51:1046-53.

22. Chiappini C. Nanoneedle-Based sensing in biological systems. ACS Sens. 2017:2:1086-102

23. Abbott J, Ye T, Ham D, Park H. Optimizing nanoelectrode arrays for scalable intracellular electrophysiology. Acc Chem Res. 2018;51:600-8.

24. Higgins SG, Stevensv MM. Extracting the contents of living cells. Nanotechnology. 2017;356:379-80.

25. Choi S, Kim H, Kim SY, Yang EG. Probing protein complexes inside living cells using a silicon nanowire-based pull-down assay. Nanoscale. 2016:8:11380-4.

26. Chiappini C, De Rosa E, Martinez JO, Liu X, Steele J, Stevens MM, Tasciotti E. Biodegradable silicon nanoneedles delivering nucleic acids intracellularly induce localized in vivo neovascularization. Nat Mater. 2015:14:532-9.

27. Chen Y, Aslanoglou S, Murayama T, Gervinskas G, Fitzgerald LI, Sriram S, Tian J, Johnston APR, Morikawa Y, Suu K, Elnathan R, Voelcker NH. Siliconnanotube-mediated intracellular delivery enables ex vivo gene editing. Adv Mater. 2020;32:e2000036.

28. Avants BW, Park H, Robinson JT. Nanotechnologies for the Bioelectronic Interface. Micro- and nanosystems for biotechnology. 2016; Chapter 6, pp. 127-142. 
29. Abbott J, Ye T, Qin L, Jorgolli M, Gertner RS, Ham D, Park H. CMOS nanoelectrode array for all-electrical intracellular electrophysiological imaging. Nat Nanotechnol. 2017;12:460-6.

30. Liu H, Bolonduro OA, Hu N, Ju J, Rao AA, Duffy BM, Huang Z, Black LD, Timko BP. Heart-on-a-chip model with integrated extra- and intracellular bioelectronics for monitoring cardiac electrophysiology under acute hypoxia. Nano Lett. 2020;20:2585-93.

31. Alexeev P, Leupold O, Sergueev I, Herlitschke M, McMorrow DF, Perry RS, Hunter EC, Rohlsberger R, Wille HC. Nuclear resonant scattering from (193)Ir as a probe of the electronic and magnetic properties of iridates. Sci Rep. 2019;9:e5097.

32. Cohen-Karni T, Lieber CM. Nanowire nanoelectronics: Building interfaces with tissue and cells at the natural scale of biology. Pure Appl Chem. 2013;85:883-901.

33. Alhmoud H, Brodoceanu D, Elnathan R, Kraus T, Voelcker NH. A MACEing silicon: towards single-step etching of defined porous nanostructures for biomedicine. Progress Mater Sci. 2019. https://doi.org/10.1016/j.pmatsci. 2019.100636.

34. Chiappini C, Liu X, Fakhoury JR, Ferrari M. Biodegradable porous silicon barcode nanowires with defined geometry. Adv Funct Mater. 2010;20:2231-9.

35. Harding FJ, Surdo S, Delalat B, Cozzi C, Elnathan R, Gronthos S, Voelcker $\mathrm{NH}$, Barillaro G. Ordered silicon pillar arrays prepared by electrochemical micromachining: substrates for high-efficiency cell transfection. ACS Appl Mater Interfaces. 2016;8:29197-202.

36. Brodoceanu D, Alhmoud HZ, Elnathan R, Delalat B, Voelcker NH, Kraus T. Fabrication of silicon nanowire arrays by near-field laser ablation and metal-assisted chemical etching. Nanotechnology. 2016;27:e075301.

37. Elnathan R, Isa L, Brodoceanu D, Nelson A, Harding FJ, Delalat B, Kraus T, Voelcker $\mathrm{NH}$. Versatile particle-based route to engineer vertically aligned silicon nanowire arrays and nanoscale pores. ACS Appl Mater Interfaces. 2015;7:23717-24.

38. Rey BM, Elnathan R, Ditcovski R, Geisel K, Zanini M, Fernandez-Rodriguez MA, Naik WV, Frutiger A, Richtering W, Ellenbogen T, Voelcker NH, Isa L. Fully tunable silicon nanowire arrays fabricated by soft nanoparticle templating. Nano Lett. 2016;16:157-63.

39. Fernandez-Rodriguez MA, Elnathan R, Ditcovski R, Grillo F, Conley GM, Timpu F, Rauh A, Geisel K, Ellenbogen T, Grange R, Scheffold F, Karg M, Richtering W, Voelcker NH, Isa L. Tunable 2D binary colloidal alloys for soft nanotemplating. Nanoscale. 2018;10:22189-95.

40. Han HJ, Jeong JW, Yang SR, Kim C, Yoo HG, Yoon JB, Park JH, Lee KJ, Kim TS, Kim SW, Jung YS. Nanotransplantation printing of crystallographic-orientation-controlled single-crystalline nanowire arrays on diverse surfaces. ACS Nano. 2017;11:11642-52.

41. Li H, Wu J, Xiao Huang ZY, Liu J, Zhang H. A Universal, rapid method for clean transfer of nanostructures onto various substrates. ACS Nano. 2014:8:6563-70.

42. Goren-Ruck L, Tsivion D, Schvartzman M, Popovitz-Biro R, Joselevich E. Guided growth of horizontal GaN nanowires on quartz and their transfer to other substrates. ACS Nano. 2014;8:2838-47.
43. Kwiat M, Cohen S, Pevzner A, Patolsky F. Large-scale ordered 1D-nanomaterials arrays: assembly or not? Nano Today. 2013;8:677-94.

44. Park H, Crozier KB. Multispectral imaging with vertical silicon nanowires. Sci Rep. 2013;3:e2460.

45. Seo K, Wober M, Steinvurzel P, Schonbrun E, Dan Y, Ellenbogen T, Crozier KB. Multicolored vertical silicon nanowires. Nano Lett. 2011;11:1851-6.

46. Qu Y, Zheng Y, Yu L, Zhou Y, Wang Y, Zhang Y, Yu Q, Chen H. A universal platform for high-efficiency "engineering" living cells: integration of cell capture, intracellular delivery of biomolecules, and cell harvesting functions. Adv Func Mater. 2019;30:e1906362.

47. Choi M, Lee SH, Kim WB, Gujrati V, Kim D, Lee J, Kim Jl, Kim H, Saw PE, Jon S. Intracellular delivery of bioactive cargos to hard-to-transfect cells using carbon nanosyringe arrays under an applied centrifugal g-force. Adv Healthc Mater. 2016;5:101-7.

48. Dixit HG, Starr R, Dundon ML, Pairs PI, Yang X, Zhang Y, Nampe D, Ballas CB, Tsutsui H, Forman SJ, Brown CE, Rao MP. Massively-parallelized, deterministic mechanoporation for intracellular delivery. Nano Lett. 2020:20:860-7.

49. Hansel CS, Crowder SW, Cooper S, Gopal S, da Cruz PJM, de Martins OL, Keller D, Rothery S, Becce M, Cass AEG, Bakal C, Chiappini C, Stevens M. Nanoneedle-mediated stimulation of cell mechanotransduction machinery. ACS Nano. 2019;13:2913-26.

50. Hansel CS, Holme MN, Gopal S, Stevens MM. Advances in high-resolution microscopy for the study of intracellular interactions with biomaterials. Biomaterials. 2020;226:e119406.

51. Rotenberg MY, Elbaz B, Nair V, Schaumann EN, Yamamoto N, Sarma N, Matino L, Santoro F, Tian B. Silicon nanowires for intracellular optical interrogation with subcellular resolution. Nano Lett. 2020;20:1226-32.

52. Santoro F, Zhao W, Joubert LM, Duan L, Schnitker J, van de Burgt $Y$, Lou HY, Liu B, Salleo A, Cui L, Cui Y, Cui B. Revealing the cell-material interface with nanometer resolution by focused ion beam/scanning electron microscopy. ACS Nano. 2017;11:8320-8.

53. Lou HY, Zhao W, Li X, Duan L, Powers A, Akamatsu M, Santoro F, McGuire AF, Cui Y, Drubin DG, Cui B. Membrane curvature underlies actin reorganization in response to nanoscale surface topography. Proc Natl Acad Sci U S A. 2019;116:23143-51.

54. Aslanoglou S, Chen Y, Oorschot V, Trifunovic Z, Hanssen E, Suu K, Voelcker $\mathrm{NH}$, Elnathan R. Efficient transmission electron microscopy characterization of cell-nanostructure interfacial interactions. J Am Chem Soc. 2020;142:15649-53.

55. Hanson L, Lin ZC, Xie C, Cui Y, Cui B. Characterization of the cellnanopillar interface by transmission electron microscopy. Nano Lett. 2012;12:5815-20

\section{Publisher's Note}

Springer Nature remains neutral with regard to jurisdictional claims in published maps and institutional affiliations.

Ready to submit your research? Choose BMC and benefit from

- fast, convenient online submission

- thorough peer review by experienced researchers in your field

- rapid publication on acceptance

- support for research data, including large and complex data types

- gold Open Access which fosters wider collaboration and increased citations

- maximum visibility for your research: over $100 \mathrm{M}$ website views per year

At $\mathrm{BMC}$, research is always in progress.

Learn more biomedcentral.com/submissions 